\title{
Polymers, An Infrangible Part of Our Life.
}

\author{
Taimoor Hassan ${ }^{1}$, Chao Zhou ${ }^{2}$, Sana Saeed ${ }^{3}$ \\ ${ }^{1}$ Lecturer, Department of Health Professional Technologies, The University of Lahore \\ ${ }^{1}$ Post Graduate Scholar, School of Pharmacy and Medicine, Changzhou University, Jiangsu, China \\ ${ }^{2}$ Associate Professor, School of Pharmacy and of Medicine, Changzhou University, Jiangsu, China \\ ${ }^{3}$ Lecturer, Department of Health Professional Technologies, The University of Lahore
}

The Polymers, a most heard word in our daily life is a macromolecule or a large molecule, which is typically a combination of plethora of subunits. We live in an era of industrial revolution where we cannot imagine life without polymers. ${ }^{1}$ They are salient part of our personal, domestic and commercial life from our DNA to giant spaceships.

Since long ago, polymers are being used in the lives of people in different aspects, but after the advent of World War II, polymers got their recognition globally. In the past, we had very limited availability of materials to sustain a civilized life. The wood, steel, stone, glass, were specifically used for construction purposes, while cotton, jute, wood and some other agricultural products were used in textile industry for cloth production. The traditional materials that people used were heavy and brittle. ${ }^{2}$ The industrial revolution of $20^{\text {th }}$ and $21^{\text {st }}$ century introduced enormous other new materials. These materials are said to be polymers, and their impact on our daily life in multiple domains is incalculable. Almost everything around us is made up of polymers, like; clothing is made up of synthetic fibers, the fiberglass, every type of plastic bag, paints, polystyrene based electronic devices, silicone heart valves, polypropylene based medical

\footnotetext{
Correspondence:

Taimoor Hassan

Email: Taimoorhassan408.th@gmail.com

Cite this editorial: Hassan T, Zhou C, Saeed S. Polymers, An Infrangible Part of Our Life. J Islamabad Med Dental Coll. 2021; 10(3): 131-132

Doi: $10.35787 /$ jimdc.v10i3.747
}

syringes, catheters, tubes, polyurethane based cushions and foams used in hospitals and the list is countless. $^{3}$

A word 'Polymer' or 'Macromolecule' is of Greek origin. In Greek the word poly means 'many' and the word meres means 'several parts'. A polymer weighs in ranges $10000-1000000 \mathrm{~g} / \mathrm{mol}$ and further consist of longs chains and structural subunits which bind together by a covalent bond specifically. ${ }^{4}$

Polymers are derived from the reactions of monomers, the sub-units. The monomers have a distinct property of reaction with same type of molecules or with different types of molecules under certain conditions to form polymer chains. The polymers like; collagen, latex, cellulose, starch etc are formed naturally while the man-made polymers are synthetic. The natural polymers are with us since the beginning, while synthetic polymers (Nylon, Polyvinyl Chloride, Polyethylene etc.) are studied widely since $20^{\text {th }}$ century. Today the polymer industry has taken over the other industries combined like; steel, copper, silver, Gold. ${ }^{5}$

Today, the polymer industry is widely used to provide comfort to humans in almost every domain of life; in fast-communications, quality agriculture, good nutrition, instant transportations, diverse clothing, business-skyscrapers, carpet highways, entertainment, advanced medical facilitation etc. In today's world, it is very difficult for us to sustain life without polymers. ${ }^{6}$ In increasing technological world, science plays a vital role in giving the solutions to expository problems like food, clean 
environment, safety, energy and ultimate health. The theory of polymers gives us a basic understanding to live a healthy life. Basic life sciences define the concept of polymers thoroughly, this includes practical, factual and theoretical knowledge. $^{5}$

Natural and Synthetic polymers can be used in organic and inorganic forms; elastomers, plastics, fibers, adhesives, ceramics, blends and composites. The basic principle applied to one polymer category is also applicable to other categories of polymers with some essential regulations and conditions. ${ }^{7}$

It is worth-mentioning that experts from all domains: Doctors, Pharmacists, Technologists, Chemical engineers, Textile engineers, Mechanical engineers, Technicians, Chemists, Research experts are directly and indirectly involved in research projects related to polymers. Surprisingly, in biomedicine, molecular biology, biophysics, polymer biology and pharmacy, the biopolymers have opened new horizons of researches. ${ }^{1}$ It is quite obvious that why the study of these giant molecules is catching the eyes of researchers in today's era. Therefore, it is crystal-clear that the polymer is not an interdisciplinary subject or a branch of chemistry, but it is itself a specialized, unique and broad discipline that covers parts of chemistry, medicine, biology, physics and many more. Science has played a tremendous role in exploring the hidden facts of nature. ${ }^{3}$ There is no ambiguity in saying that today the biopolymer branch, is taking over the classical fields of physics, chemistry, material engineering and even polymer engineering and is widely used in treatment, diagnosis of diseases and advanced application of medical devices.

Keywords: Polymers, Biopolymers, Natural, Synthetic, Monomer.

Acknowledgments:

Authors like to acknowledge 'JIMDC' for the publication of this Editorial

\section{References}

1. Namazi H. Polymers in our daily life. Bioimpacts. 2017;7(2):73. Doi:10.15171/bi.2017.09.

2. Ramesh Kumar S, Shaiju P, O'Connor KE. Bio-based and biodegradable polymers-State-of-the-art, challenges and emerging trends. Curr Opin Green Sustain Chem. 2020; 21(2):75-81. Doi: 10.1016/j.cogsc.2019.12.005.

3. Hong $M$, Chen EY. Future directions for sustainable polymers. Trends Chem. 2019;1(2). Doi: 10.1016/j.trechm.2019.03.004:148-51.

4. Lutz JF. Can Life Emerge from Synthetic Polymers? Isr J Chem. 2020; 60(1-2):151-9. Doi: 10.1002/ijch.201900110.

5. Badia JD, Gil-Castell O, Ribes-Greus A. Long-term properties and end-of-life of polymers from renewable resources. Polym Degrad Stab. 2017; 13(7):35-57.

Doi: 10.1016/j.polymdegradstab.2017.01.002.

6. Ma X, Wen G. Development history and synthesis of super-absorbent polymers: a review. Journal of Polymer Research. 2020; 27(6):1-2. Doi:10.1007/s10965-020-02097-2.

7. Ramesh P, Vinodh S. State of art review on Life Cycle Assessment of polymers. International Journal of Sustainable Engineering. 2020; 13(6):411-22. Doi: 10.1080/19397038.2020.1802623. 